\title{
PENGARUH FINANCIAL KNOWLEDGE DAN FINANCIAL SOCIALIZATION TERHADAP FINANCIAL LITERACY PADA INDIVIDU YANG MENGGUNAKAN LAYANAN DIGITAL PERBANKAN
}

\author{
William Sebastian \\ Program Studi Magister Manajemen Universitas Tarumanagara \\ william_s_g@yahoo.com
}

Masuk : 07-12-2020, revisi : 13-02-2021, diterima untuk diterbitkan : 13-02-2021

\begin{abstract}
The purpose of this research is to examine the effect of financial knowledge and financial socialization on financial literacy. This study uses 414 samples, consisting of parties who use the digital banking system mobile banking in DKI Jakarta. A partial least square was applied to analyze the association of financial knowledge and financial literacy with financial socialization as the mediation variable. This study reveals a direct effect of financial knowledge on financial literacy. But financial socialization has no significant impact on financial literacy. This study provides input for the Indonesian people to encourage investment intentions for investors and potential investors in using mobile banking services so that investment in mutual funds will be easier and increase. This research is an outreach for investors and potential investors to use mobile banking in investing in finance in Indonesia.
\end{abstract}

Keywords: Financial Knowledge, Financial Socialization, Financial Literacy

\begin{abstract}
Abstrak: Tujuan penelitian ini adalah untuk menguji pengaruh pengetahuan keuangan dan sosialisasi keuangan terhadap literasi keuangan. Penelitian ini menggunakan 414 sampel yang terdiri dari pihak-pihak yang menggunakan sistem perbankan digital mobile banking di DKI Jakarta. Partial Least Square digunakan untuk menganalisis hubungan antara pengetahuan keuangan dan literasi keuangan dengan sosialisasi keuangan sebagai variabel mediasi. Studi ini mengungkapkan pengaruh langsung pengetahuan keuangan terhadap literasi keuangan. Namun sosialisasi keuangan tidak berpengaruh signifikan terhadap literasi keuangan. Penelitian ini memberikan masukan bagi masyarakat Indonesia untuk mendorong niat berinvestasi bagi investor dan calon investor dalam menggunakan layanan mobile banking agar investasi pada reksa dana semakin mudah dan meningkat. Penelitian ini bertujuan untuk menjangkau investor dan calon investor untuk menggunakan mobile banking dalam berinvestasi di bidang keuangan di Indonesia.
\end{abstract}

Kata Kunci: Pengetahuan Keuangan, Sosialisasi Keuangan, Literasi Keuangan

\section{PENDAHULUAN}

Pada era globalisasi, kebutuhan manusia tidak bisa lepas dari teknologi. Penggunaan layanan perbankan digital sudah marak digunakan oleh masyarakat, khususnya layanan digital perbankan mobile banking. Mobile banking mempermudah masyarakat untuk melakukan transaksi dan investasi keuangan dengan mudah tanpa harus pergi ke bank setiap saat. Literasi keuangan digital masyarakat baru mencapai $35.5 \%$ dan penggunaan layanan digital pada masyarakat baru 31.26\%. Masyarakat yang menggunakan mobile banking dalam kisaran frekuensi 1-2 kali dalam sebulan hingga sangat jarang masih 55\% jumlahnya, sedikit lebih dominan daripada masyarakat yang sering menggunakan mobile banking (Alika, 2020).

Penggunaan uang merupakan hal yang penting pada saat ini, namun masih banyak masyarakat yang rendah dalam memutuskan untuk melakukan investasi. Tahun 2019, hanya $2 \%$ saja masyarakat yang baru melakukan investasi, dan sisanya habis untuk membayar kebutuhan bulanan (Siregar, 2019). Financial knowledge dan financial socialization menjadi pengaruh individu dalam melakukan keputusan keuangan yang baik. Financial knowledge 
merupakan kemampuan seorang individu untuk memahami kondisi keuangan dan konsep keuangan sehingga dapat mengelola sumber daya keuangan yang dimiliki dengan baik dan dapat hidup dengan sejahtera di masa yang akan datang dengan melakukan money management (Hogarth \& Hilgert, 2002).

Bhushan dan Medury (2014) menyatakan bahwa financial knowledge mempunyai hubungan yang signifikan terhadap financial literacy. Menurut Sohn et al. (2012), Putri dan Djuminah (2016), agensi dari financial socialization memiliki pengaruh signifikan terhadap financial literacy. Pengaruh lingkungan terhadap keputusan keuangan individu disebut juga financial socialization, dimana financial socializaiton agency seperti lingkungan formal dan informal, terutama orang tua, berpengaruh dalam memberikan sosialisasi mengenai uang untuk mementukan keputusan keuangan seorang individu (Danes, 1994).

\section{Tujuan Penelitian}

Penelitian ini bertujuan untuk mengetahui:

1. Apakah Financial Knowledge memiliki pengaruh terhadap Financial Literacy?

2. Apakah Financial Socialization memiliki pengaruh terhadap Financial Literacy?

\section{TINJAUAN PUSTAKA}

Theory of Planned Behavior, terdapat tiga komponen dasar yang dapat mempengaruhi pengambilan keputusan seseorang, yaitu: attitudes toward the behavior (ATT), subjective norms regarding the behavior $(S N)$, and perceived control over the behavior $(P B C)$ (Sussman $\&$ Gifford, 2019). Perubahan perilaku individu (behavior) didasari oleh niat (intention) berperilaku yang dimiliki individu tersebut. Attitude towards behavior mendorong individu untuk semakin kuat mengambil keputusan keuangan berdasarkan pengetahuan yang dimilikinya. Sehingga, financial knowledge dapat berpengaruh terhadap pengambilan keputusan keuangan seseorang, yaitu financial literacy.

Aspek Financial Literacy, mencakup 5 (lima) konsep keuangan (Lusardi, 2008), yaitu pengetahuan dasar mengenai keuangan pribadi, pengetahuan mengenai manajemen uang, pengetahuan mengenai kredit dan utang, pengetahuan mengenai tabungan dan investasi, dan pengetahuan mengenai resiko.

Financial Socialization concept terdiri dari 2 unsur, yaitu (a) family socialization processes dan (b) financial socialization outcomes. Sikap, pengetahuan, dan kemampuan finansial berpengaruh terhadap sosial karakteristik individu dan berkembang seiring waktu (Sherraden et al., 2017).

Financial Literacy merupakan "pengetahuan, keterampilan, dan keyakinan yang mempengaruhi sikap dan perilaku untuk meningkatkan kualitas pengambilan keputusan dan pengelolaan keuangan dalam rangka mencapai kesejahteraan" (Otoritas Jasa Keuangan, 2017) dan menurut Kaufman (2017), dapat disimpulkan bahwa literasi keuangan adalah kemampuan dari seseorang dalam membuat keputusan finansial yang baik dan efektif.

Financial Knowledge, diartikan sebagai dan disimpulkan bahwa pengetahuan keuangan merupakan pedoman seseorang dalam memperlakukan uangnya dengan baik (Hilgert et al., 2003). Penelitian Chen dan Volpe (1998) menunjukkan siswa yang kurang berpengetahuan cenderung membuat kesalahan dalam membuat keputusan keuangan, sehingga disimpulkan bahwa mahasiswa yang kurang memiliki pengetahuan tentang personal finance atau memiliki pengetahuan yang rendah akan membatasi kemampuan mereka untuk membuat keputusan keuangan.

Financial Socialization, diartikan bahwa sosialisasi finansial merupakan proses pencapaian dan pengembangan nilai, sikap, standar, norma, pengetahuan, dan perilaku yang berpengaruh terhadap keberlangsungan finansial dan kesejahteraan individu (Danes, 1994). Sohn et al. (2012) mengemukakan bahwa remaja yang menggunakan media sebagai sumber utama sosialisasi keuangan dan punya akun bank relatif memiliki literasi keuangan yang cukup tinggi. 


\section{METODOLOGI PENELITIAN}

Jenis penelitian ini adalah jenis penelitian deskriptif kuantitatif. Sumber data yang digunakan dalam penelitian ini adalah data primer dan instrumen pengumpulan data dengan menggunakan kuesioner yang disebarkan melalui Google Forms. Populasi dalam penelitian ini adalah nasabah yang menggunakan layanan digital mobile banking pada seluruh jenis bank yang sudah bekerja dan berdomisili di DKI Jakarta. Indikator pada penelitian ini diambil dari Marshall dan Magruder (1960), Hogarth dan Hilgert (2002), van Rooij et al. (2011), Remund (2010), Shim et al. (2010), Atkinson dan Messy (2012) dan menggunakan skala likert 1-10 dengan 1 menunjukan "sangat tidak setuju" dan 10 "sangat setuju".

Metode yang digunakan dalam penelitian ini adalah purposive sampling. Dari 508 responden yang terkumpul, terdapat 414 responden yang memenuhi kriteria sebagai pengguna layanan digital mobile banking yang sudah bekerja dan tinggal di DKI Jakarta dan kemudian diolah menggunakan SmartPLS 3. Partial Least Square (PLS) adalah metode analisis yang sangat kuat karena tidak berdasarkan pada banyak asumsi. Sampel yang harus dikumpulkan tidak harus besar dan data tidak harus berdistribusi normal multivariate (indikator dengan skala kategori ordinal, interval, dan rasio dapat digunakan dalam model yang sama) (Wold, 1985).

\section{HASIL DAN PEMBAHASAN}

Responden yang berpartisipasi dalam penelitian ini merupakan pengguna mobile banking yang sudah bekerja dan tinggal di wilayah DKI Jakarta. Terdapat 486 orang menggunakan $\mathrm{m}$ banking dan 22 orang tidak penggunakan m-banking, 466 orang yang sudah bekerja dan 42 orang belum bekerja, dan 448 orang tinggal di DKI Jakarta dan 60 orang tinggal di luar DKI Jakarta, sehingga didapatkan 414 responden yang layak masuk kriteria penelitian. Untuk domisili responden, didapatkan 81 orang tinggal di Jakarta Utara dan Kepulauan Seribu, 137 orang tinggal di Jakarta Barat, 72 orang tinggal di Jakarta Selatan, 75 orang tinggal di Jakarta Pusat, 77 orang tinggal di Jakarta Timur, dan 66 lainnya tinggal di luar DKI Jakarta dan tidak masuk kriteria penelitian.

Hasil penelitian PLS terdiri dari outer model dan inner model. Outer model pada penelitian ini menggunakan indikator reflektif, model pengukuran (outer model) dievaluasi menggunakan convergent validity dan discriminant validity dari indikator dan composite reliability untuk blok indikator. Loading factor dapat diterima apabila indikator memiliki nilai $>0,7$ sedangkan untuk nilai AVE > 0,5 yang bisa diikutsertakan (Henseler et al., 2009), cross loading factor pada konstruk yang dituju harus lebih tinggi/besar dibandingkan dengan nilai loading dengan konstruk yang lain, dan data yang memiliki nilai composite reliability $>0,7$ dinyatakan dapat diterima (Henseler et al., 2009). Nilai GoF pada penelitian ini adalah sebesar 0,624 yang berarti tingkat kesesuaian dan kelayakan model penelitian ini dinyatakan besar.

Hasil uji validitas SmartPLS menyatakan bahwa seluruh indikator pertanyaan pada outer loading dan cross loading dinyatakan valid sehingga tidak perlu ada indikator yang dibuang. Standar pengukuran Average Variance Extracted (AVE) pada seluruh variabel financial knowledge, financial literacy, financial socialization dinyatakan valid masing-masing sebesar $0.731,0.744$, dan 0.785 yang berarti bahwa seluruh variabel diatas telah memenuhi kelayakan evaluasi karena memiliki nilai koefisien sebesar AVE >0,5. Hasil uji reliabilitas pada nilai composite reliability menunjukan masing-masing variabel financial knowledge, financial literacy, financial socialization dinyatakan reliabel yaitu $0.967,0.970$, dan 0.978 maka composite reliability $>0.8$. $R$-square pada penelitian ini menunjukan bahwa financial literacy dapat dijelaskan oleh variabel financial knowledge dan financial socialization yaitu sebesar $82,6 \%$ dan financial socialization dapat dijelaskan oleh variabel financial knowledge yaitu sebesar $61.2 \%$.

Suatu variabel dinyatakan signifikan apabila nilai t-statistik minimal 1,96 dan $p$-value memiliki nilai lebih kecil dari nilai alpha 0,05 . 
Tabel 1

Tabel Uji Hipotesis

\begin{tabular}{|c|c|c|}
\hline Variabel & T Statistics & P Values \\
\hline Financial Knowledge -> Financial Literacy & 23.356 & 0.000 \\
\hline Financial Socialization -> Financial Literacy & 1.336 & 0.182 \\
\hline
\end{tabular}

Hasil path coefficient menunjukan bahwa financial knowledge memiliki pengaruh signifikan terhadap financial literacy, begitu juga dengan financial knowledge memiliki pengaruh signifikan terhadap financial socialization. Namun financial socialization tidak memiliki pengaruh signifikan terhadap financial literacy. Financial socialization tidak dapat memediasi variabel financial knowledge terhadap financial literacy.

H1: Financial Knowledge memiliki pengaruh terhadap Financial Literacy

Variabel financial knowledge memiliki pengaruh signifikan terhadap financial literacy pada individu pengguna layanan digital perbankan mobile banking di DKI Jakarta. Kontribusi indikator terbesar dimiliki oleh risk and return. Indikator tersebut membahas investasi dengan laba tinggi memiliki resiko kerugian yang tinggi pula, sehingga mempengaruhi seorang individu yang memiliki informasi mengenai keuangan akan lebih cerdas dan berhati-hati dalam mengambil keputusan keuangan. Individu tersebut akan lebih memahami bagaimana cara mengelola keuangan, menggunakan uang, dan melakukan investasi dengan sebaik mungkin. Keputusan individu untuk menggunakan mobile banking akan meningkat apabila mereka paham mengenai manfaat yang didapatkan dari penggunan layanan digital perbankan. Hasil penelitian ini searah dengan penelitian Bhushan dan Medury (2014), Chen dan Volpe (1998), Setiawati dan Nurkhin (2018).

H2: Financial Socialization memiliki pengaruh terhadap Financial Literacy

Variabel financial socialization tidak memiliki pengaruh signifikan terhadap financial literacy pada individu pengguna layanan digital perbankan mobile banking di DKI Jakarta. Hasil penelitian menunjukan bahwa sebagian besar individu memperoleh pengaruh sosialisasi keuangan dari agen sosialisasi keuangan, seperti orang tua, teman kerja, media, maupun dari lingkungan formal. Minimnya pengetahuan keuangan dari pihak yang mensosialisasikan, maka mempengaruhi seorang individu untuk mendapatkan informasi buruk mengenai keuangan dan mengakibatkan kesalahan dalam mengambil keputusan keuangan. Tanpa adanya pengetahuan yang baik mengenai manfaat penggunaan mobile banking maka tidak dapat mempengaruhi keputusan individu untuk menggunakan layanan digital perbankan mobile banking. Hasil penelitian ini bertolak belakang dengan penelitian Dewi et al. (2017), Sohn et al. (2012),Putri dan Djuminah (2016).

\section{DAFTAR PUSTAKA}

Alika, R. (2020). Literasi keuangan digital rendah, Jokowi minta fintech perluas peran. KataData. https://katadata.co.id/ameidyonasution/berita/5fac4a1893be8/literasikeuangan-digital-rendah-jokowi-minta-fintech-perluas-peran

Atkinson, A., \& Messy, F.-A. (2012). Measuring financial literacy: Results of the OECD INFE pilot study. In OECD Working Papers on Finance, Insurance and Private Pensions (Issue 15). https://doi.org/10.1787/bb2cd70c-en

Bhushan, P., \& Medury, Y. (2014). An empirical analysis of inter linkages between financial attitudes, financial behaviour and financial knowledge of salaried individuals. Indian Journal of Commerce \& Management Studies, 5(3), 1161-1201. http://www.scholarshub.net/index.php/ijcms/article/view/190/184

Chen, H., \& Volpe, R. P. (1998). An analysis of personal financial literacy among college students. Financial Services Review, 7(2), 107-128. https://doi.org/10.1016/S10570810(99)80006-7

Danes, S. M. (1994). Parental perceptions of children's financial socialization. Journal of Financial Counseling and Planning, 5(5), 127-149. https://www.afcpe.org/wpcontent/uploads/2018/10/vol-58-1.pdf 
Dewi, N., Rusdarti, \& Sunarto, S. (2017). Pengaruh lingkungan keluarga, teman sebaya, pengendalian diri dan literasi keuangan terhadap perilaku konsumtif mahasiswa. Journal of Economic Education, 6(1), 29-35.

https://journal.unnes.ac.id/sju/index.php/jeec/article/view/14618/7974

Henseler, J., Ringle, C. M., \& Sinkovics, R. R. (2009). The use of partial least squares path modeling in international marketing. Advances in International Marketing, 20, 277-319. https://doi.org/10.1108/S1474-7979(2009)0000020014

Hilgert, M. A., Hogarth, J. M., \& Beverly, S. G. (2003). Household financial management: The connection between knowledge and behavior. Federal Reserve Bulletin, Jul, 309322. https://www.federalreserve.gov/pubs/bulletin/2003/0703lead.pdf

Hogarth, J. M., \& Hilgert, M. A. (2002). Financial knowledge, experience and learning preferences: Preliminary results from a new survey on financial literacy. Consumer Interest Annual, 48(1), 1-7.

https://www.consumerinterests.org/assets/docs/CIA/CIA2002/hogarth-hilgert_financial knowledge.pdf

Kaufman, R. (2017). Financial attitude and financial literacy. MyFICO. https://www.myfico.com/credit-education/blog/financial-attitude-and-financial-literacy

Lusardi, A. (2008). Household saving behavior: The role of financial literacy, information, and financial education programs (No. 13824; NBER Working Paper). https://doi.org/10.3386/w13824

Marshall, H. R., \& Magruder, L. (1960). Relations between parent money education practices and children's knowledge and use of money. Child Development, 31(2), 253-284. https://doi.org/10.1111/j.1467-8624.1960.tb04964.x

Otoritas Jasa Keuangan. (2017). Salinan surat edaran Otoritas Jasa Keuangan nomor 30 /SEOJK.07/2017. https://www.ojk.go.id/id/kanal/edukasi-dan-perlindungankonsumen/regulasi/surat-edaran-ojk/Documents/SAL SEOJK 30 - Literasi Keuangan.pdf

Putri, B. B. K., \& Djuminah. (2016). Peran agen sosialisasi finansial, pengalaman finansial dan perilaku terhadap uang dalam membentuk literasi finansial pada mahasiswa [Universitas Sebelas Maret Surakarta]. https://digilib.uns.ac.id/dokumen/download/228951/MjI4OTUx

Remund, D. L. (2010). Financial literacy explicated: The case for a clearer definition in an increasingly complex economy. Journal of Consumer Affairs, 44(2), 276-295. https://doi.org/10.1111/j.1745-6606.2010.01169.x

Setiawan, \& Nurkhin, A. (2018). Pengujian dimensi konstruk literasi keuangan mahasiswa. Economic Education Analysis Journal, 6(3), 727-736. https://journal.unnes.ac.id/sju/index.php/eeaj/article/view/20283/9618

Sherraden, M., Birkenmaier, J., McClendon, G. G., \& Rochelle, M. (2017). Financial capability and asset building in social work education: Is it "The Big Piece Missing?" Journal of Social Work Education, 53(1), 132-148. https://doi.org/10.1080/10437797.2016.1212754

Shim, S., Barber, B. L., Card, N. A., Xiao, J. J., \& Serido, J. (2010). Financial socialization of first-year college students: The roles of parents, work, and education. Journal of Youth and Adolescence, 39(12), 1457-1470. https://doi.org/10.1007/s10964-009-9432-x

Siregar, A. (2019). Survei IMS 2019: Millennieal tidak suka menabung. IDN Times. https://www.idntimes.com/business/economy/ananta-fitri/survei-ims-2019-millenniealtidak-suka-menabung

Sohn, S. H., Joo, S. H., Grable, J. E., Lee, S., \& Kim, M. (2012). Adolescents' financial literacy: The role of financial socialization agents, financial experiences, and money attitudes in shaping financial literacy among South Korean youth. Journal of Adolescence, 35(4), 969-980. https://doi.org/10.1016/j.adolescence.2012.02.002 
Sussman, R., \& Gifford, R. (2019). Causality in the theory of planned behavior. Personality and Social Psychology Bulletin, 45(6), 920-933. https://doi.org/10.1177/0146167218801363

van Rooij, M., Lusardi, A., \& Alessie, R. (2011). Financial literacy and stock market participation. Journal of Financial Economics, 101(2), 449-472. https://doi.org/10.1016/j.jfineco.2011.03.006

Wold, H. (1985). Partial least squares. In S. Kotz \& N. L. Johnson (Eds.), Encyclopedia of Statistical Sciences (6th ed., pp. 581-591). John Wiley \& Sons. 